\title{
Próby spawania laserowego niskostopowej wysokowytrzymałej stali o strukturze martenzytycznej
}

\author{
The study of laser welding low alloy high strength steel \\ with a martensitic structure
}

\section{Streszczenie}

W artykule przedstawiono badania dotyczące spawania wiązką laserową niskostopowej wysokowytrzymałej stali o strukturze martenzytycznej DOCOL 1200M $\left(R_{m}=1200 \mathrm{MPa}\right)$ o grubości 1,8 mm. Proces spawania został przeprowadzony przy zmiennej energii linowej spawania w zakresie od $25 \mathrm{~J} / \mathrm{mm}$ do $55 \mathrm{~J} / \mathrm{mm}$. Badania nieniszczące pozwoliły sklasyfikować złącza w poziomie jakości B zgodnie z ISO 13919. Przeprowadzone badania niszczące wykazały, że wzrost energii linowej spawania powoduje podwyższenie własności plastycznych połączeń przy jednoczesnym obniżeniu własności wytrzymałościowych, poniżej wytrzymałości materiału rodzimego. Przy zastosowaniu niskich energii linowych spawania wiązką laserową (na poziomie $25 \mathrm{~J} / \mathrm{mm}$ ) istnieje możliwość uzyskania złączy spawanych ze stali DOCOL 1200M o wytrzymałości równej wytrzymałości materiału rodzimego, co jest bardzo trudne do osiągnięcia przy spawaniu łukowym stali o tak wysokiej wytrzymałości.

Słowa kluczowe: stal DOCOL 1200M; spawanie laserowe; martenzyt

\begin{abstract}
In this paper researches on laser welding of low-alloyed high strength DOCOL $1200 \mathrm{M}$ steel sheets $1,8 \mathrm{~mm}$ thick were presented. Sheets were welded in range of linear energy from $25 \mathrm{~J} / \mathrm{mm}$ up to $54 \mathrm{~J} / \mathrm{mm}$. NDT tests allows to classify all joints at level B according to ISO 13919 standards. Destructive tests indicates that increase of linear energy results in increase of plasticity and decrease of strength properties, lower than base material. Using low linear energy in laser welding of DOCOL $1200 \mathrm{M}$ steel joints (at level $25 \mathrm{~J} / \mathrm{mm}$ ) allows to obtain tensile strength the same as for base material what is not possible to achieve during arc welding of this type high-strength steel (1200 MPa).
\end{abstract}

Keywords: DOCOL 1200M steel; laser welding; martensitic

\section{Wstęp}

Producenci stali wytwarzają coraz to nowsze materiały, o lepszych własnościach, które są odpowiedzią na zapotrzebowanie między innymi przemysłu motoryzacyjnego. Przyczyną tego są wysokie wymagania związane z bezpieczeństwem użytkowników oraz ciągły trend redukcji wagi wytwarzanych konstrukcji. Pozwala to na sporą redukcje masy pojazdów, zmniejszenie ich zapotrzebowania na paliwo oraz zmniejszenie emisji szkodliwych gazów do otoczenia. W celu zaspokojenia tego zapotrzebowania przemysłu motoryzacyjnego powstały stale o wysokiej wytrzymałości AHSS (Advanced High-Strength Steel). Materiały te sprawdziły się świetnie w produkcji pojazdów za sprawą trzech bardzo istotnych cech: dużej wytrzymałości na rozciąganie, do $1700 \mathrm{MPa}$, dużej granicy plastyczności, do $1450 \mathrm{MPa}$ oraz dużego wydłużenia A80, do $30 \%$ [1 $\div 4$ ]. Istotnym jest również fakt, że stosunkowo łatwa jest obróbka plastyczna oraz obróbka skrawaniem tych stali. Stale wysokowytrzymałe AHSS chętnie wykorzystywane są w przemyśle motoryzacyjnym, ponieważ dają możliwość zmniejszenia grubości blach karoseryjnych oraz elementów nośnych karoserii przy jednoczesnym wzroście własności mechanicznych w zestawieniu ze stalami konwencjonalnymi. Dodatkowym atutem stali AHSS jest stosunkowo niska cena, za sprawą małej ilości dodatków stopowych w stali. Pomimo faktu, że stale projektowane były $z$ myśla o łączeniu ich poprzez procesy spajania, niektóre z nich wciąż stanowią problem w opraco-

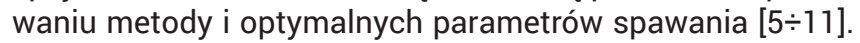
Dużym wyzwaniem jest spawanie wysokowytrzymałej stali DOCOL 1200M o strukturze martenzytycznej, przeznaczonej głównie na wytwarzanie zderzaków samochodowych, belek bocznych oraz innych elementów zapewniających bezpieczeństwo użytkownika pojazdów mechanicznych.

Dr hab. inż. Jacek Górka - Katedra Spawalnictwa, Politechnika Śląska w Gliwicach, mgr inż. Andrzej Ozgowicz - Dyplomant Katedry Spawalnictwa.

Autor korespondencyjny/Corresponding author: jacek.gorka@polsl.pl 
Tablica I. Skład chemiczny i własności mechaniczne stali martenzytycznej DOCOL 1200M

Table I. The chemical composition and mechanical properties of martensitic DOCOL 1200M steel

\begin{tabular}{|c|c|c|c|c|c|c|c|c|c|c|c|}
\hline \multicolumn{12}{|c|}{ Stężenie pierwiastków, \% } \\
\hline C & $\mathrm{Si}$ & $\mathrm{Mn}$ & $P$ & S & Al & $\mathrm{Nb}$ & V & $\mathrm{Ni}$ & $\mathrm{Cr}$ & $\mathrm{N}$ & $\mathrm{Ce}^{*}$ \\
\hline 0,113 & 0,22 & 1,58 & 0,01 & 0,002 & 0,035 & 0,016 & 0,01 & 0,04 & 0,04 & 0,006 & 0,39 \\
\hline \multicolumn{12}{|c|}{ Własności mechaniczne } \\
\hline \multicolumn{4}{|c|}{$\begin{array}{l}\text { Wytrzymałość na rozciąganie } \mathrm{Rm} \text {, } \\
\mathrm{MPa}\end{array}$} & \multicolumn{4}{|c|}{$\begin{array}{c}\text { Granica plastyczności Re, } \\
\text { MPa }\end{array}$} & \multicolumn{4}{|c|}{$\begin{array}{l}\text { Wydłużenie } \mathrm{A}_{80}, \\
\%\end{array}$} \\
\hline \multicolumn{4}{|c|}{1260} & \multicolumn{4}{|c|}{1060} & \multicolumn{4}{|c|}{5} \\
\hline
\end{tabular}

Tablica II. Parametry spawania laserowego stali DOCOL 1200M o grubości 1,8 mm Table II. Laser welding parameters DOCOL $1200 \mathrm{M}$ steel with a thickness of 1,8 mm

\begin{tabular}{|c|c|c|c|c|}
\hline $\begin{array}{c}\text { Oznaczenie } \\
\text { złącza }\end{array}$ & $\begin{array}{c}\text { Moc } \\
{[\mathrm{W}]}\end{array}$ & $\begin{array}{c}\text { Prędkość przetapiania } \\
\text { [mm/min] }\end{array}$ & $\begin{array}{c}\text { Energia liniowa } \\
\text { [J/mm] }\end{array}$ & $\begin{array}{c}\text { Średnica ogniska } \\
\text { wiązki laserowej } \\
\text { [mm] }\end{array}$ \\
\hline $1 . x$ & 1500 & 2000 & 45 & 0,3 \\
\hline $2 . x$ & 2500 & 6000 & 25 & 0,3 \\
\hline $3 . x$ & 1800 & 2000 & 55 & 0,6 \\
\hline $4 . x$ & 3500 & 6000 & 35 & 0,6 \\
\hline
\end{tabular}

\section{Badania własne}

Celem badań było określenie własności złączy doczołowych blach o grubości 1,8 mm ze stali niskostopowej wysokowytrzymałej DOCOL 1200M, o strukturze martenzytycznej spawanych wiązką laserową przy zastosowaniu zmiennej energii liniowej spawania (od $25 \mathrm{~J} / \mathrm{m}$ do $55 \mathrm{~J} / \mathrm{mm}$ ). Rzeczywisty skład chemiczny i własności stali DOCOL 1200M przedstawia tablica I, a strukturę rysunek 1 .

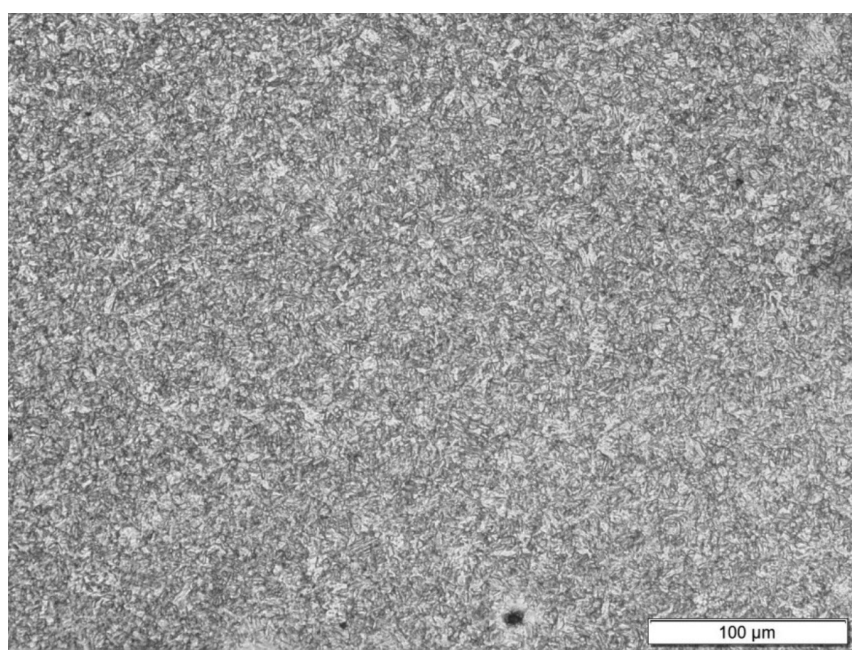

Rys. 1. Mikrostruktura stali DOCOL $1200 \mathrm{M}$

Fig. 1. The microstructure of DOCOL $1200 \mathrm{M}$ steel

\section{Proces spawania}

Złącza spawane zostały wykonane w Instytucie Spawalnictwa w Gliwicach na zrobotyzowanym stanowisku wyposażonym w robota przemysłowego KUKA KR 20/2HA, na którego kiści zamocowano głowicę lasera dyskowego TruDisk 12002 firmy TRUMPF (rys. 2). Ogniskowa soczewki kolimatora wynosiła $f_{c}=200 \mathrm{~mm}$, ogniskowa soczewki skupiającej $\mathrm{f}_{\mathrm{og}}=300 \mathrm{~mm}$. Do transportu wiązki laserowej wykorzystano światłowody o dwóch różnych średnicach: $\mathrm{d}_{\mathrm{sw}}=$ $0,2 \mathrm{~mm}$ oraz $\mathrm{d}_{\mathrm{sw}}=0,4 \mathrm{~mm}$. Korzystając ze wzoru (1) wyliczona została średnica ogniska wiązki laserowej dla obu przypadków, wynosząca analogicznie $\mathrm{d}_{\mathrm{og}}=0,3 \mathrm{~mm}$ i $\mathrm{d}_{\mathrm{og}}=0,6 \mathrm{~mm}$.

Podczas procesu spawania wykonano 16 złączy doczołowych, w pozycji podolnej z ukosowaniem na l, po 4 przy każdym układzie parametrów. Proces spawania odbywał się w osłonie gazu ochronnego, którym był argon o natężeniu przepływu $20 \mathrm{l} / \mathrm{min}$ podawany przez dyszę czterorurkową. Podczas prób spawania zmianie podlegała średnica ogniska wiązki laserowej, moc wiązki oraz prędkość spawania, tablica II. Przed spawaniem w celu redukcji odkształceń spawalniczych blachy zostały sczepione w trzech miejscach (na początku, w środku i na końcu).

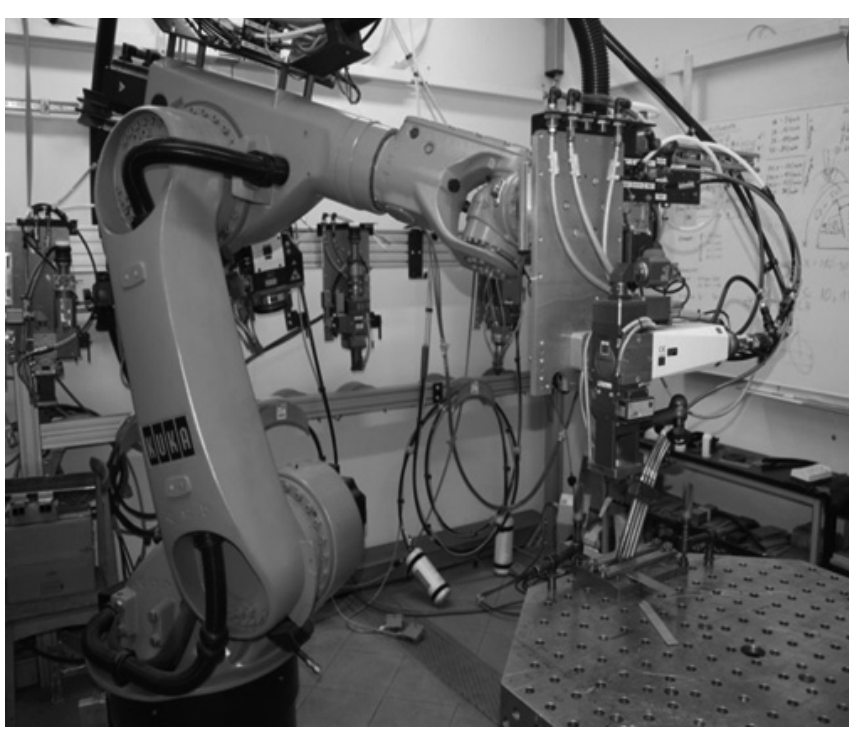

Rys. 2. Stanowisko do zrobotyzowanego spawania laserowego wykorzystane $w$ badaniach

Fig. 2. The position of robotic laser welding used for studies 


\section{Badania złączy spawanych}

Uzyskane złącza spawane po przeprowadzeniu badań wizualnych na podstawie wymagań PN-EN ISO 13919-1:2002 poddano badaniom niszczącym $\mathrm{w}$ takim zakresie jak:

- badania wytrzymałości na rozciąganie zgodnie z PN-EN ISO 6892-1:2010 na maszynie wytrzymałościowej typ ZWICK/ROELL Z 330RED na próbkach pobranych zgodnie z PN-EN ISO 4136:2011;

- próba zginania poprzecznego złącza doczołowego z rozciąganiem od strony lica spoiny (FBB) oraz zginania złącza doczołowego z rozciąganiem od strony grani spoiny (RBB) na podstawie normy PN-EN ISO 5173:2010. Próby zginania przeprowadzono za pomocą maszyny ZWICK/ ROELL Z 330RED $z$ dodatkowym modułem dla prób zginania;

- badania metalograficzne makroskopowe na mikroskopie świetInym stereoskopowym Olympus SZX9; próbki do badań trawiono odczynnikiem Adlera;

- badania metalograficzne mikroskopowe na mikroskopie świetlnym NIKON ECLIPSE MA100; próbki do badań trawiono w nitalu;

- pomiar twardości za pomocą urządzenia Vickers 401MVD firmy Wilson Wolpert, przy obciążeniu 1 kg, wzdłuż jednej linii pomiarowej.

\section{Analiza wyników badań}

Przeprowadzone badania wizualne wykonanych złączy spawanych nie wykazały wad spawalniczych wychodzących na powierzchnię typu: pęknięcia, porowatość, przyklejenia, braki przetopu. Złącza spawane spełniały wymagania poziomu jakości B zgodnie z ISO 13919-1, jedynie w przypadku złączy wykonanych energią linową $25 \mathrm{~J} / \mathrm{mm}$ można zauważyć przesunięcie liniowe, które obniża poziom jakości. Również badania makroskopowe nie wykazały niezgodności spawalniczych w obszarze spoiny i SWC (rys. 3). Można zaobserwować, że wraz ze wzrostem energii liniowej spawania rośnie szerokość spoiny oraz szerokość obszaru SWC.

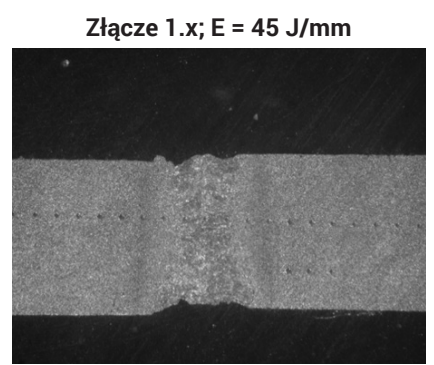

Złącze 3.x; $\mathrm{E}=55 \mathrm{~J} / \mathrm{mm}$

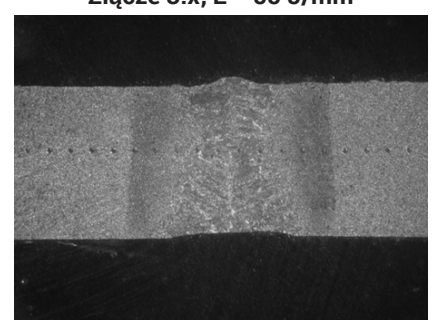

Rys. 3. Makrostruktura złączy spawanych laserowo stali DOCOL 1200M

Fig. 3. Macrostructure laser welded joints DOCOL $1200 \mathrm{M}$ steel

Badania mikroskopowe w obszarze spoiny ujawniły w każdym przypadku strukturę martenzytyczną, przy czym wraz ze wzrostem energii liniowej spawania wielkość igieł martenzytu rośnie, zwłaszcza w stosunku do materiału rodzimego. W SWC dochodzi do odpuszczenia struktury martenzytycznej. Wraz ze wzrostem energii liniowej spawania stopień odpuszczenia rośnie, rysunek 4.

Analiza wyników badań niszczących doczołowych złączy spawanych stali DOCOL 1200M wiązką laserową wykazała, że uzyskane złącza próbne spełniają wymagania ISO 15614-11, tabl. III. Wraz ze wzrostem energii linowej spawania z $25 \mathrm{~J} / \mathrm{mm}$ do $55 \mathrm{~J} / \mathrm{mm}$ następuje spadek wytrzymałości na rozciąganie
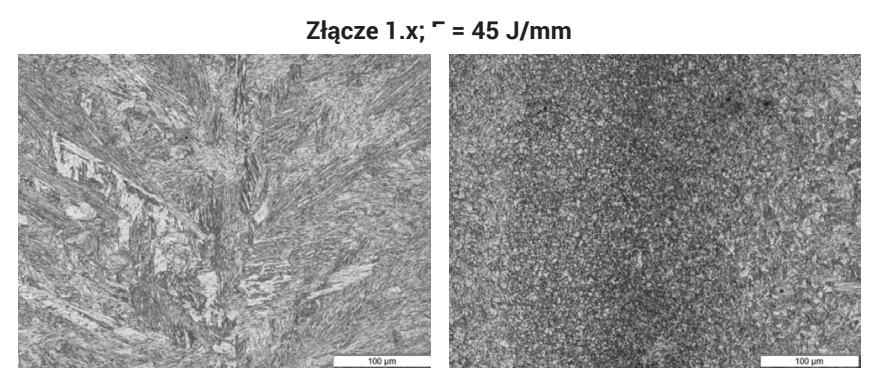

Złącze 2.x;
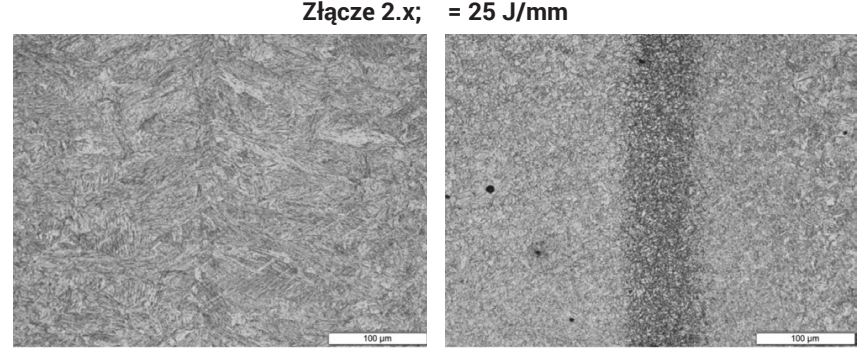

Złącze 3.x
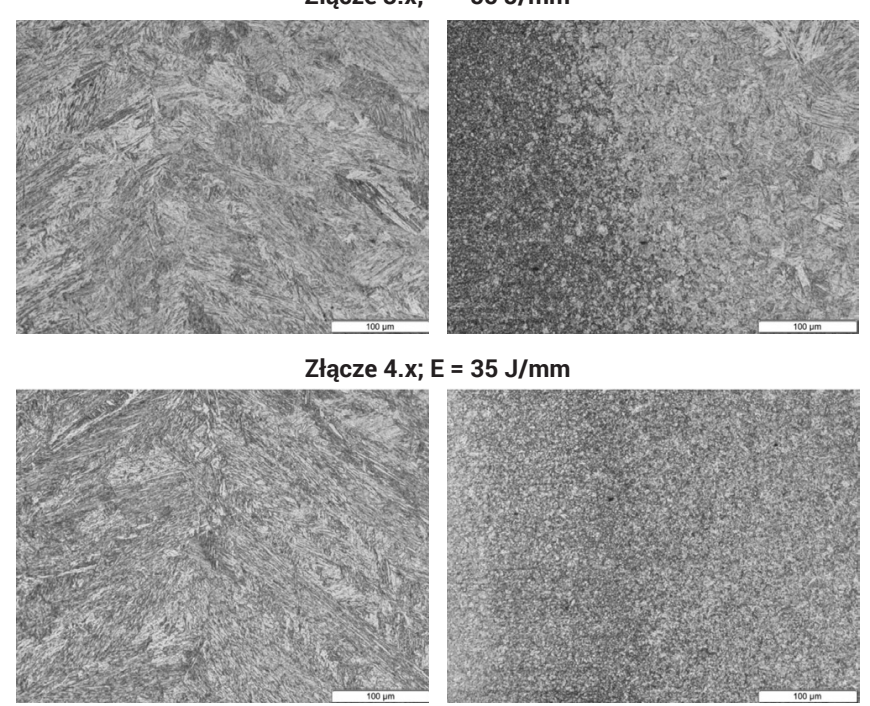

Rys. 4. Mikrostruktura złączy spawanych laserowo stali DOCOL 1200M Fig. 4. Microstructure laser welded joints DOCOL 1200M steel

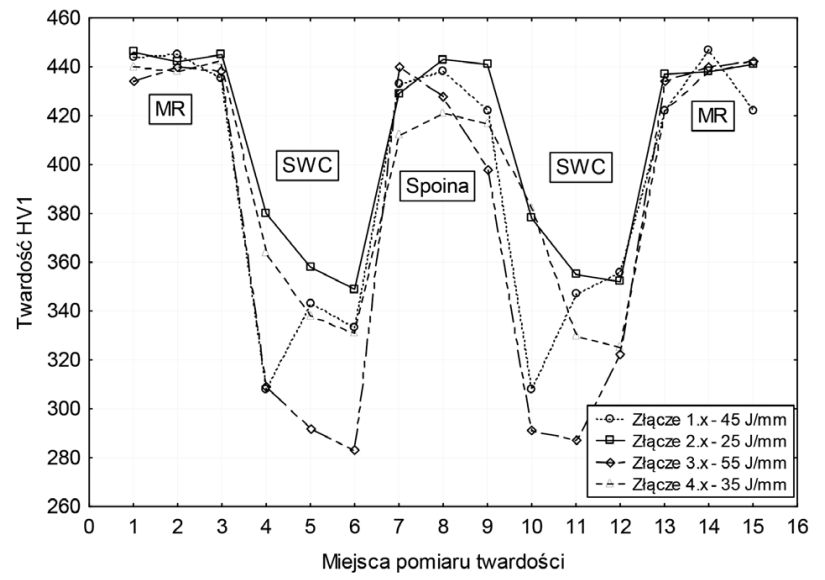

Rys. 5. Rozkład twardości złączy spawanych wiązką laserową stali DOCOL 1200M

Fig. 5. Distribution of hardness of the laser welded joints DOCOL $1200 \mathrm{M}$ steel 
Tablica III. Własności wytrzymałościowe i plastyczne złącza laserowo stali DOCOL 1200M

Table III. Mechanical and plastic properties of laser welded joint steel DOCOL 1200M

\begin{tabular}{|c|c|c|c|}
\hline \multicolumn{2}{|c|}{ Rozciąganie* } & \multicolumn{2}{|c|}{ Zginanie*$^{\star}$, kąt gięcia, ${ }^{\circ}$} \\
\hline $\mathrm{R}_{\mathrm{m}}, \mathrm{MPa}$ & Miejsce zerwania & Lico & Grań \\
\hline \multicolumn{4}{|c|}{ Złącze 1; $\mathrm{E}=45 \mathrm{~J} / \mathrm{mm}$} \\
\hline 1150 & SWC & 66 & 69 \\
\hline \multicolumn{4}{|c|}{ Złącze 2; E = $25 \mathrm{~J} / \mathrm{mm}$} \\
\hline 1240 & SWC & 68 & 72 \\
\hline \multicolumn{4}{|c|}{ Złącze 3; E = 55 J/mm } \\
\hline 1120 & Materiał rodzimy & 140 & 138 \\
\hline \multicolumn{4}{|c|}{ Złącze 4; $\mathrm{E}=35 \mathrm{~J} / \mathrm{mm}$} \\
\hline 1200 & Linia wtopienia & 84 & 83 \\
\hline
\end{tabular}

z $1240 \mathrm{MPa}$ do $1100 \mathrm{MPa}$, przy wytrzymałości na rozciąganie materiału rodzimego na poziomie $1260 \mathrm{MPa}$. Przy niskich energiach linowych spawania zerwane nastąpiło w obszarze materiału rodzimego, wzrost energii spawania spowodował rozrost ziarna w obszarze SWC i w tym miejscu inicjowało się zerwanie złączy. Statyczna próba zginania wykazała, że najwyższymi własnościami plastycznymi charakteryzują się złącza wykonane przy najwyższej energii linowej $(54 \mathrm{~J} / \mathrm{mm})$, dla których osiągnięto kąt gięcia na poziomie $140^{\circ}$, tablica III.
Przeprowadzone pomiary twardości HV1, potwierdziły wyniki badań metalograficznych mikroskopowych. W obszarze spoiny wykonanej przy najniższej energii linowej $(25 \mathrm{~J} / \mathrm{mm})$ uzyskane twardości były zbliżone do twardości materiału rodzimego, około $440 \mathrm{HV} 1$, wraz ze wzrostem energii linowej twardość spoiny malała do poziomu $400 \mathrm{HV} 1$, przy energii $55 \mathrm{~J} / \mathrm{mm}$. W obszarze SWC, która została odpuszczona również wraz ze wzrostem energii linowej spawania twardość maleje z 360 HV1 do 280 HV1, rysunek 5.

\section{Podsumowanie}

Przeprowadzone badania procesu spawania wiązką laserową stali DOCOL 1200M o grubości 1,8 mm, wykazały, że istnieje możliwość wykonania złączy spawanych, spełniających kryteria normy ISO 15614-11, jedynie w przypadku próby zginania nie zostały spełnione wymagana normy. Pomimo wysokiego równoważnika węgla stali AHSS DOCOL 1200M możliwe jest uzyskanie złączy spawanych wiązka laserową z zapewnieniem wysokich własności wytrzymałościowych. Wszystkie wykonane złącza w obszarze spoiny charakteryzują się strukturą martenzytu iglastego, o zmiennej wielkości igieł w zależności od ilości dostarczonej energii. W SWC materiał rodzimy został odpuszczony, co spowodowało powstanie strefy zmiękczonej. Wielkość spoiny oraz strefy zmiękczonej w badanych złączach wzrastała wraz ze wzrostem energii liniowej procesu spawania. W celu redukcji wielkości strefy zmiękczonej, podczas spawania należy stosować jak najmniejsze możliwe energie liniowe spawania. Przeprowadzona próba zginania wykazała, że złącza ze stali DOCOL 1200M spawane wiązką laserową z zastosowanymi parametrami cechują się niską plastycznością w obszarze złącza. Jednak w przypadku tej stali, jej główną własnością eksploatacyjną jest wytrzymałość na rozciąganie. Przy zastosowaniu niskich energii linowych spawania wiązką laserową istnieje możliwość uzyskania złączy spawanych o wytrzymałości równej wytrzymałości materiału rodzimego, co jest bardzo trudne do osiągnięcia przy spawaniu łukowym stali o tak wysokiej wytrzymałości [12,13].

\section{Literatura}

[1] Grajcar A., Różański M.: Spawalność wysokowytrzymałych stali wielofazowych AHSS, Przegląd Spawalnictwa nr 3/2014, str. 22-27.

[2] Nishioka K., Ichikawa K.: Progress in termomechanical control of steel plates and their commercialization, Science and Technology of Advanced Materials, vol. 13, No. 2, April 2012, pp. 1-20.

[3] Krajewski S., Nowacki J.: Mikrostruktura i właściwości stali o wysokiej wytrzymałości AHSS, Przegląd Spawalnictwa nr 7/2011, str. 45-50.

[4] Stano S.: Spawanie laserowe blach o zróżnicowanej grubości przeznaczonych na półfabrykaty karoserii samochodowych typu tailored blanks, Biuletyn Instytutu Spawalnictwa nr 2/2005, str. 24-28.

[5] Chen B., Yu H.: Hot ductility behaviour of V-N and V-Nb microalloyed steels, International Journal of Minerals, Metallurgy and Materials, vol. 19, No. 6, June 2012, p. 525

[6] Lee, H. Shin, K. Park: Evaluation of high strength TMCP steel weld for use in cold regions, Journal of Constructional Steel Research 74 (2012) pp. 134-139.

[7] Górka J.: Weldability of thermomechanically treated steels having a high yield point, Archives of Metallurgy and Materials, Volume 60, Issue 1/2015, pp. 469-475

[8] Lisiecki A.: Diode laser welding of high yield steel. Proc. of SPIE Vol. 8703, Laser Technology 2012: Applications of Lasers, 87030S (January 22, 2013), DOI: 10.1117/12.2013429.
[9] Adamczyk J., Opiela M.: Influence of the thermo-mechanical treatment parameters on the inhomogeneity of the austenite structure and mechanical properties of the Cr-Mo steel with $\mathrm{Nb}, \mathrm{Ti}$ and $\mathrm{B}$ microadditions, Journal of Materials Processing Technology, vol. 157-158, 2004, pp. 456-461.

[10] Górka J.: Study of structural changes in S700MC steel thermomechanically treated under the influence of simulated welding thermal cycles, Indian Journal of Engineering and Materials Sciences, Vol. 22, October 2015, pp. 497-502.

[11] Grajcar A., Różański M., Stano S.: Effect of heat input on microstructure and hardness distribution of laser welded Si-AI TRIP-type steel, Advances Material Science Engineering. 2014, Article ID 658947, pp. 1-8.

[12] Godwin K., Yong O., Microstructure and fatigue performance of butt-welded joints in advanced high-strength steels, Materials Science \& Engineering A 597 (2014), pp. 342-348.

[13] Wang W., Li M., He C., at al.: Experimental study on high strain rate behavior of high strength $600-1000 \mathrm{MPa}$ dual phase steels and 1200MPa fully martensitic steels. Materials and Design (2013), 47, pp. 510-521. 